\title{
Supporting bereavement and complicated grief in primary care: a realist review
}

\section{Caroline Pearce $^{1 *}$, Geoff Wong ${ }^{2}$, Isla Kuhn ${ }^{3}$, Stephen Barclay ${ }^{4}$ \\ ${ }^{1}$ Research Associate, Primary Care Unit, Department of Public Health and Primary Care, University of Cambridge, Cambridge, UK; ${ }^{2}$ General Practitioner and Associate Professor, Nuffield Department of Primary Care Health Sciences, University of Oxford, Oxford, UK; ${ }^{3}$ Head of Medical Library Services, University of Cambridge Medical Library, University of Cambridge, Cambridge, UK; ${ }^{4} \mathrm{GP}$ and University Senior Lecturer, Primary Care Unit, Department of Public Health and Primary Care, University of Cambridge, Cambridge, UK}

\begin{abstract}
Background: Bereavement can have significant impacts on physical and mental health, and a minority of people experience complicated and prolonged grief responses. Primary care is ideally situated to offer bereavement care, yet UK provision remains variable and practitioners feel uncertain how best to support bereaved patients.
\end{abstract}

Aim: To identify what works, how, and for whom, in the management of complicated grief (CG) in primary care.

Design \& setting: A review of evidence on the management of CG and bereavement in UK primary care settings.

Method: A realist approach was taken that aims to provide causal explanations through the generation and articulation of contexts, mechanisms, and outcomes.

Results: Forty-two articles were included. Evidence on the primary care management of complicated or prolonged grief was limited. GPs and nurses view bereavement support as part of their role, yet experience uncertainty over the appropriate extent of their involvement. Patients and clinicians often have differing views on the role of primary care in bereavement. Training in bereavement, local systems for reporting deaths, practitioner time, and resources can assist or hinder bereavement care provision. Practitioners find bereavement care can be emotionally challenging. Understanding patients' needs can encourage a proactive response and help identify appropriate support.

Conclusion: Bereavement care in primary care remains variable and practitioners feel unprepared to provide appropriate bereavement care. Patients at higher risk of complicated or prolonged grief may fail to receive the support they need from primary care. Further research is required to address the potential unmet needs of bereaved patients.

\section{How this fits in}

Bereavement can lead to prolonged and complicated grief responses impacting on physical and mental health. Evidence from this review shows that bereavement care is considered an important part of primary care, although the way in which it is provided remains inconsistent, and clinicians experience many ambiguities as to the appropriate extent of their involvement with bereaved patients. Following bereavement, patients expect acknowledgement from their GP; however, clinicians often feel 
unprepared and lack the appropriate resources or training to provide bereavement support. Broader concerns over clinical intervention into bereavement mean bereavement care is not always recognised as a legitimate part of general practice. Awareness of CG among GPs appears low, indicating a gap in education and training in this area.

\section{Introduction}

Most people adapt to bereavement without formal support. However, a minority of bereaved people develop complicated or prolonged grief symptoms, experiencing disruption in daily functioning. ${ }^{1,2}$ Complicated grief (CG) or Prolonged grief disorder (PGD) is a mental health condition involving a pervasive grief response that persists for more than 6 months following a loss. ${ }^{3}$ Patients experiencing severe grief responses may benefit from healthcare support and onward referral for targeted treatment. ${ }^{4-7}$

GPs are frequently identified as ideally placed to offer bereavement support, ${ }^{8,9}$ yet primary care practitioners are often uncertain how to best support bereaved people ${ }^{10}$ and awareness of CG or PGD is low. ${ }^{11}$ In the UK, there remains no consistent approach to general bereavement care, ${ }^{4}$ or to managing severe grief symptoms, despite protocols for general practice proposed over 20 years ago. ${ }^{8}$ NHS policy recognises the importance of bereavement care, ${ }^{12}$ but nationally provision is varied. ${ }^{13-16}$

The COVID-19 pandemic has highlighted the need to improve support for bereaved patients; ${ }^{17}$ it is predicted that circumstances related to the pandemic will increase the numbers of people at risk of complicated grieving. ${ }^{18-21}$ Evidence to inform practitioners and policymakers is vital to ensure bereaved patients are supported over the immediate and longer-term impact.

The authors sought to review the existing evidence to identify what works, how, and for whom in the management of CG in primary care, focusing on the implications for the UK.

\section{Method}

A realist approach was used to conduct this review, as detailed in the published protocol. ${ }^{22}$ Realist review is an interpretive, theory-driven approach to evidence synthesis that is rooted in the principles of 'realism', a philosophy of science. Realist reviews build explanations for outcomes that take the form of context-mechanism-outcome configurations (CMOCs). ${ }^{23}$ This approach maintains that aspects of interventions can function as a context to influence the responses of participants (mechanisms) that cause particular outcomes, and is suitable for understanding complex social problems, such as bereavement, where interventions involve multifaceted processes. Box 1 details the review stages based on Pawson's ${ }^{23}$ protocol. For further details, see Supplementary Box 1.

Patient and public members, and stakeholders provided feedback and advice on the review findings. These were incorporated into the development of the final programme theory and helped shape the final recommendations on primary care interventions.

\section{Results}

Forty-two articles were included in the analysis (see Figure 1). Most articles reported research $(n=35)$; three commentaries and four letters were also included. Research articles comprised 15 qualitative studies, 11 surveys, six mixed-methods studies, two randomised controlled trials, and one systematic review. Full details are provided in Supplementary Table 1.

No UK articles were found on primary care management of complicated or prolonged grief. Outside the UK evidence was also limited, with only three articles identified that included analysis of practitioner understanding of PGD or CG. ${ }^{24-26}$

Broadening the review to general bereavement care, it was found that primary care faced challenges in three areas: identifying bereaved patients; bereaved patients' expectations; and responding to bereaved patients. In the following sections, a narrative explanation for each issue is provided, referenced with the related CMOCs. Example CMOCs for each area are listed in Table 1; the full list of $21 \mathrm{CMOCs}$ with examples of supporting data are provided in Supplementary Table 2. The final programme theory is presented in Figure 2.

\section{Identifying bereaved patients}

Inconsistent systems and processes to report deaths were described (CMOC1).9,27,28 Death registers improved awareness but difficulties were encountered if the deceased person was registered at a 
Box 1 Realist review stages

An initial programme theory was devised, drawing on the knowledge of the research team. To identify the focus of the review, an exploratory search was conducted using keywords in MEDLINE/PubMed and Google Scholar. Following initial searches, the limited Step 1. Locating evidence on the management of complicated grief in primary care settings in the UK and other settings was apparent, and the existing theories scope of the searches broadened to include general bereavement care.

Step 2. Searching The search strategy was conducted with the support of an information specialist (IK). The main search strategy used combinations for evidence of search terms for the concepts 'bereavement', 'complicated grief', 'primary care', and 'United Kingdom' to run four searches (see Supplementary Box S2). In August 2019 the following databases were searched: MEDLINE, Embase, CINAHL (the Cumulative Index to Nursing and Allied Health Literature), PsycINFO, Web of Science, Scopus, ASSIA (Applied Social Sciences Index and Abstracts), Sociological abstracts and SCIE (Social Care Institute for Excellence) Social Care Online.

Citation chasing and manual searches of the reference lists of articles and reports were also completed.

Following initial screening, the limited evidence on the management of complicated grief in UK primary care was apparent. Therefore, an additional search using a refined search filter for the United Kingdom was undertaken in January 2020 to ensure all relevant UK literature was retrieved.

Screening Titles and abstracts were screened by CP against the inclusion and exclusion criteria. Inclusion criteria were studies of: (1) adults (aged $>18$ years) who have lost a significant other and whose grief and/or bereavement experience is considered complicated or prolonged in accordance with a variety of criteria (formal diagnosis of ICD/DSM [International Classification of Diseases/the Diagnostic and Statistical Manual of Mental Disorders] or other not required); and (2) where care is sought and received in primary care settings, focusing on the UK but also including studies from other high and middle income countries where psychosocial conditions can, routinely, be managed in primary care. All study designs were included. Exclusion criteria were studies of neo- and peri-natal bereavement, bereaved children and adolescents, military bereavement, non-death bereavement, grief of healthcare professionals.

Judgments on the relevance of the data within these articles for programme theory development were reviewed by the whole project team.

Step 3. Selecting Full-text documents were selected for inclusion based on their ability to provide relevant data to the review. This included articles articles that directly investigated, reviewed, and discussed how bereavement and complicated grief is managed in primary care settings, in the UK and elsewhere. CP read the full texts and classified them into categories of high and low relevance, based on her judgments on the relevance of the data within these articles for programme theory development. These decisions were then reviewed by SB and GW.

At the point of data inclusion based on relevance, when needed, the trustworthiness and rigour of the methods used in each study to gather relevant data was also assessed. One means of assessing rigour was examining whether the study methods had been clearly explained and justified. For example, if using questionnaires or diagnostic tools, then the trustworthiness of data would be considered greater if the questionnaire or tool had been tested and validated.

A range of articles were included in the synthesis, including empirical studies, grey literature, and non-empirical articles such as editorials and opinion pieces. Articles were not excluded on the basis of rigour alone if the article contained data relevant to the development of the programme theory.

Realist reviews are a type of configurational review, where data are interpreted and used to develop theoretical explanations of phenomena, in this case bereavement and complicated grief in primary care. To build these explanations, even less rigorous data can be useful. Assessments of rigour of included data tend to be undertaken when there is a paucity of data to inform contextmechanism-outcome configurations (CMOCs). It is also equally, if not more, important to judge the explanatory powers of any theories developed, and this was done in the review using the criteria of consilience, simplicity, and analogy at the level of the $\mathrm{CMOC}$ and programme theory. A more in-depth explanation and justification of the approach may be found in Wong $2018 .{ }^{85}$

Step 4. Extracting The articles were coded in NVivo (version 12), by CP, and initial codes were discussed and refined through iterative discussions with and organising GW and SB. As analysis continued, a refined version of the programme theory was developed. Codes were developed by referring data back to the refined programme theory and codes were applied deductively with new codes created as needed (inductively). A realist logic of analysis was applied to the data and sections of texts found within each broad conceptual theme.

Step 5. Working across and within coded-data extracts, CMOCs were developed as part of an iterative development of causal explanations Synthesising This included comparing and contrasting data presented in different articles, and making judgments about whether similarities the evidence between findings presented in different sources were adequate to form patterns in the development of CMOCs and programme and drawing theory.

conclusions The final product of this stage was a refined realist programme theory that explained how bereaved patients are identified and managed in primary care. The programme theory formed the basis of the implications for practice.

different practice to the bereaved patient (CMOC2) ${ }^{29,30}$ Learning of deaths could be opportunistic. ${ }^{31}$ GPs reported feeling let down by services or processes if unaware their patients had experienced a recent bereavement (CMOC2). . $24,31^{2}$

Most GPs and district nurses considered bereavement support part of caring for the overall health of their patients, and their professional responsibility (CMOC3). ${ }^{31-34}$ When the deceased person was their patient, bereavement support was viewed as an extension of that care. ${ }^{35,36} \mathrm{~A}$ sense of uncertainty over the appropriate extent of clinician involvement in bereavement was also reported (CMOC3). ${ }^{31,37-}$ ${ }^{40}$ Bereavement care involvement depended not only on perception of role, but also clinicians' capacity. ${ }^{33,41}$ GPs described lack of time as a primary barrier to engagement with bereavement (CMOC4). ${ }^{24,27,41}$ 


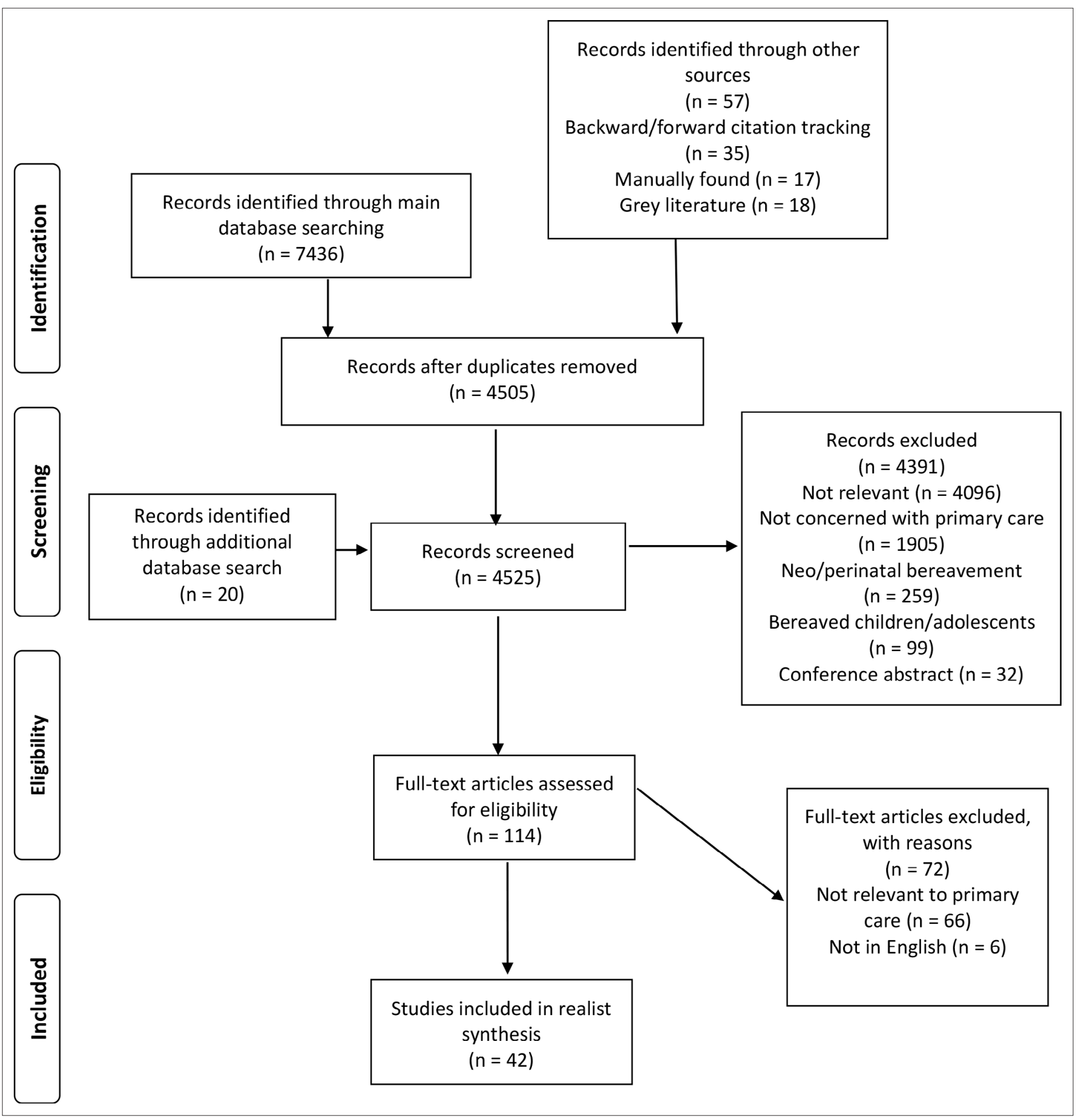

Figure 1 Article selection process

Continuity of care and a deeper involvement with patients increased likelihood of a proactive response to bereavement (CMOC5). 9,27,35,36,39,40,42 Greater knowledge of patient preferences and needs could allow the clinician to target support and provide support on an individual level (CMOC6). ${ }^{31,43}$ For example, clinicians considered a patient's family and social support when judging how a patient was coping. ${ }^{44}$ Patients also felt bereavement support was most helpful when the staff member was known to them. ${ }^{45}$ For those who did not have a strong relationship and/or little knowledge of the 
Table 1 Themes with accompanying examples of context-mechanism-outcome configurations

\begin{tabular}{|c|c|}
\hline Theme & Example context-mechanism-outcome configurations (CMOCs) \\
\hline $\begin{array}{l}\text { Identifying bereaved } \\
\text { patients }\end{array}$ & $\begin{array}{l}\text { If there are no systematic and consistent processes for recording deaths and bereavement } \\
\text { (C) clinicians may not be able to identify the bereaved patient }(\mathrm{O}) \text {, because of a lack of } \\
\text { awareness (M) (CMOC1) } \\
\text { When clinicians have a pre-existing knowledge about the preferences of a recently } \\
\text { bereaved person (C), they are more likely to make contact }(\mathrm{O}) \text {, because of their familiarity } \\
\text { [of their preference] (M) (CMOC5) }\end{array}$ \\
\hline $\begin{array}{l}\text { Bereaved person's } \\
\text { expectations of what } \\
\text { primary care can } \\
\text { provide }\end{array}$ & $\begin{array}{l}\text { When a patient has a bereavement }(C) \text {, most will expect to be contacted after a } \\
\text { bereavement }(\mathrm{O}) \text {, because they believe clinicians are meant to care for them in the hour } \\
\text { of their need }(\mathrm{M})(\mathrm{CMOC}) \\
\text { When a person is suffering from bereavement }(\mathrm{C}) \text {, they may be unable to seek help or ask } \\
\text { for help (O), because they feel overwhelmed (M) and/or hopeless }(\mathrm{M})(\mathrm{CMOC} 11)\end{array}$ \\
\hline $\begin{array}{l}\text { Responding to } \\
\text { bereaved patients }\end{array}$ & $\begin{array}{l}\text { When clinicians have had limited education in the diagnosis and management of } \\
\text { bereavement }(C) \text {, they find dealing with such patients challenging }(O) \text {, because of their } \\
\text { knowledge gaps }(\mathrm{M})(\mathrm{CMOC} 13) \\
\text { Whether or not professional training has been undertaken, when dealing with patient } \\
\text { bereavement (C) clinicians find the experience uncomfortable or unpleasant }(\mathrm{O}) \text { because } \\
\text { such encounters can be emotionally charged and distressing }(\mathrm{M})(\mathrm{CMOC} 17) \\
\text { When clinicians have personal and experiential knowledge of bereavement }(\mathrm{C}) \text { they } \\
\text { have a better understanding of how to manage bereaved patients }(\mathrm{O}) \text {, because they can } \\
\text { empathise (M) and appreciate (M) their needs (CMOC19) }\end{array}$ \\
\hline
\end{tabular}

For full list of CMOCs with accompanying quotes see Supplementary Table S2

bereaved patient's preferences, clinicians were less likely to initiate contact owing to fears of intruding (CMOC5)..$^{9,31,32,34}$

\section{Bereaved patients' expectations}

Most patients expected proactive contact from their GP following a bereavement — described as a telephone call, letter, or other acknowledgement - and viewed this as part of the clinician's job (CMOC7). ${ }^{45-48}$ By contrast, some patients felt GP involvement in bereavement was not relevant, ${ }^{48}$ and others reported there was 'no point' discussing bereavement with their GP (CMOC8, 9). ${ }^{49}$

What shaped patient expectations was unclear: one study indicated that expectations were informed by how patients viewed the role of the GP, and their perceived relationship with their GP. ${ }^{46}$ Some patients described feeling unable to approach their doctor owing to feeling overwhelmed by grief, $^{50-52}$ and for certain types of death, feelings of shame and stigma discouraged disclosure to their GP $(C M O C 11,12) .{ }^{48,53}$ Patients expressed worry about wasting the GP's time or acting as a

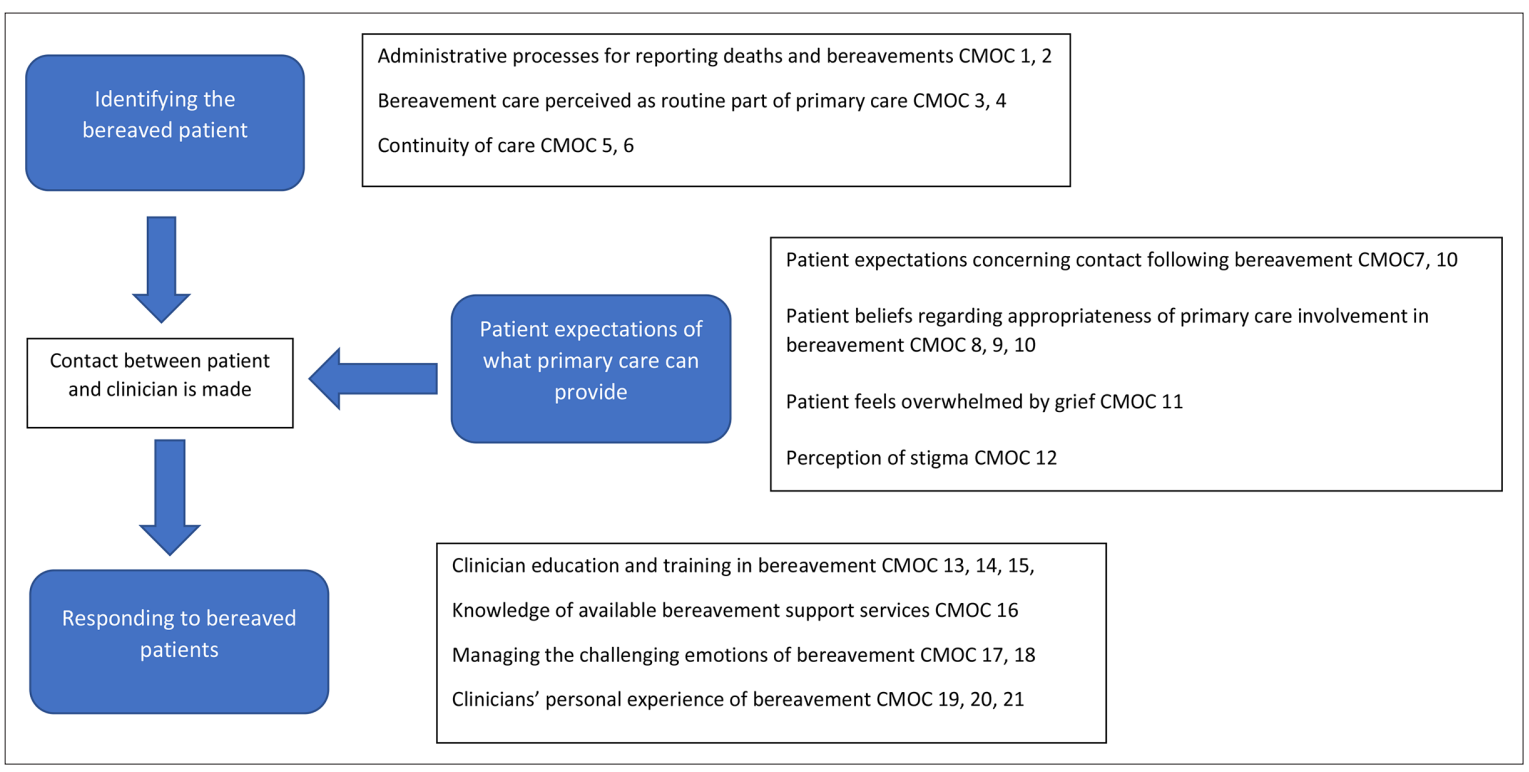

Figure 2 Programme theory of supporting bereavement and complicated grief in primary care. CMOC = context-mechanism-outcome configurations 
'nuisance'. ${ }^{47}$ Further, patients were concerned that other health complaints might be 'trivialised' as part of a grief reaction, ${ }^{45}$ and described fears of being given medication for their bereavement when instead they sought a listening ear or information (CMOC9). ${ }^{48}$

If GPs were not contacted by patients, they would assume that the patient was coping (CMOC10). ${ }^{28,31,40}$ When patients took the initiative to contact, GPs took these requests more seriously. ${ }^{31}$

Initial support was offered in most cases but longer term GPs took a reactive role. ${ }^{10,35-37}$ GPs assumed social support networks were generally the most appropriate means of bereavement support, and a minority of patients also held this view (CMOC9, 10). Professional intervention was viewed as something that might 'weaken' informal support networks. ${ }^{35-37,40}$

\section{Responding to bereaved patients}

Clinicians reported feeling unprepared to manage bereavement. ${ }^{32,40,54-56}$ Even with training, clinicians reported low confidence. ${ }^{24}$ Knowledge of contemporary theories of grief was low, and outdated stage models of grief were often utilised. ${ }^{27,28,40,57} \mathrm{GPs}^{\prime}$ ability to identify CG risk factors was poor, ${ }^{25}$ but agreed that sudden death, previous mental health history, and death of a child presented high risk of complications (CMOC13). ${ }^{27,40,50}$

Knowledge gaps concerning local bereavement services and where to refer patients was reported, causing delayed or inappropriate referrals, ${ }^{58}$ and an increased likelihood of prescribing medication. 9,25,50,51 Some clinicians were hesitant to refer if they believed that further support for bereavement was not useful $(\mathrm{CMOC} 15,16) . .^{40}$

For some, personal experiences of bereavement and/or cultural or religious beliefs were more influential than formal training (CMOC14). ${ }^{33,35,40,59}$ Clinicians with personal bereavement experience reported increased confidence in dealing with bereaved patients and improved empathy and understanding (CMOC19). ${ }^{32,34,60}$ Clinician interest in palliative care and bereavement increased with age. ${ }^{32,35}$ Personal loss also increased confidence in diagnosing PGD. ${ }^{24}$

Clinicians reported finding bereavement care emotionally challenging (CMOC17).9,27,33,34,59,61 Distressed patients could cause discomfort and feelings of helplessness. ${ }^{9,33,34}$ Perceived comfort levels with crying were associated with clinician responsiveness to the patient's grief. ${ }^{27}$ Clinicians identified with the bereaved patient, for instance, in the type of death and/or family circumstances, which both increased attentiveness and provoked emotional responses (CMOC20). 9,34,35,42,59 Clinicians also experienced grief toward deceased patients and at times guilt or regret, which fostered wariness about bereavement care involvement (CMOC21). 9,28,33,35,59

For patients, the opportunity to speak about their grief and to be listened to was important (CMOC18, 21). ${ }^{27,43,46-48,53,62}$ Clinician avoidance of discussing the loss was viewed as negative and dismissive, ${ }^{48}$ whereas displaying emotions, being attentive to patient feelings, and, in some cases, physical touch were viewed positively. ${ }^{46}$ Perceived negative responses from clinicians could increase difficulties in the grieving process $(\mathrm{CMOC} 18)^{25,40}$.

\section{Discussion}

\section{Summary}

Bereavement care is considered an important part of primary care; however, provision remains inconsistent and clinicians experience ambiguities concerning the appropriate extent of their involvement with bereaved patients. Practitioners encounter practical challenges in terms of not being aware about deaths, but bereavement can also be confronting as practitioners, at times, struggle to support distressed grieving patients and manage their own emotions.

The clear education and training needs notwithstanding, clinicians described feeling unprepared, and at times unsupported to manage bereaved patients. Positive attributes of general practice, particularly the trust and established relationships that come with having a continuity of care and/or having an understanding of patient preferences and needs were described as beneficial in knowing how and when to approach patients following bereavement.

In terms of primary care management of CG or PGD, a lack of literature was found; further research and improved training and education to guide primary care practice are needed in this area. ${ }^{50,63}$ 
Box 2 Implications for improving bereavement care in primary care practice

- Consider developing and implementing local strategies for death notification, which might include a death register (CMOCs 1, 2, 3)

- Seek an understanding of individual patient preferences: what type of bereavement support does a patient want? (CMOCs 5, 6)

- Initiate contact when patient bereavement is known; for example, by a phone call or condolence letter (CMOCs 7, 8, 9, 10, 11, 12)

- When contacting patients include details about available local support services and invite them to make an appointment if they are experiencing problems (CMOCs 8, 9, 12)

- Where appropriate, utilise link workers to help connect patients with local support services or community groups (CMOCs 8, 9, 12, 16)

- When consulting with bereaved patients utilise active listening skills: feeling listened to may be of the most value to patients (CMOCs 18, 21)

- Revising medical education and training to include up-to-date grief theories. This could include, for example, bereaved people speaking about their experiences (CMOCs 13, 14, 17, 19, 20, 21)

- Further training such as a short course to help clinicians who may need support with their own experiences of bereavement when managing a patient (CMOCs 13, 17, 19, 20, 21)

\section{Comparison with other literature}

Issues facing primary care raised by this review are not new, and debates over the appropriate role of the GP in bereavement care appear little changed from over 20 years ago. ${ }^{8,64,65}$ A previous review of bereavement care in primary care ${ }^{10}$ found that, although clinicians see bereavement care as an important part of their work, they receive little training and variation exists in practice. Only 15 articles published since 2011 were identified as relevant, indicating that evidence in this area remains limited. A US review reported similar limitations. ${ }^{63}$

Review findings have unearthed the importance of attitudes, assumptions, and expectations of bereavement care held by both clinicians and patients, suggesting an attitudinal component that needs addressing in interventions for both general bereavement and for CG or PGD. ${ }^{66}$ While mental health care is well integrated into general practice, clinician attitudes towards bereavement care appear hesitant. Clinical intervention into bereavement remains controversial across a number of specialties, including general practice. ${ }^{66-69}$ PGD has only recently been recognised as a clinical diagnosis; with increased training and awareness among primary care clinicians, attitudes and understanding of CG and PGD may improve. Nonetheless, bereavement is an intensely painful experience with no rapid or easy solution; addressing the support needs of bereaved people might be perceived as a timeconsuming prospect. Underlying this is a concern of medicalising a social experience, creating a need for health services to respond. ${ }^{35}$ However, maintaining that bereavement is solely the responsibility of social networks and community is not consistent with the holistic and compassionate care that characterises general practice.

Relying on patients to seek care, encouraged in recent UK policy changes, ${ }^{70}$ may be inappropriate for bereavement. Presently, bereaved patients and clinicians appear to have conflicting views on whose responsibility it is to initiate contact; in assuming that patients are coping, clinicians may be unaware that many of their patients want and expect some form of support. ${ }^{71}$

Grief is in many ways an 'invisible condition'72 and discussing bereavement experiences can be challenging for patients. ${ }^{73}$ Public awareness of complicated and prolonged grief is low, and susceptible to negative perceptions. ${ }^{74}$ Clinicians also struggle to know how to communicate with bereaved patients ${ }^{75}$ and how to address their needs. ${ }^{76}$ Education needs are apparent and while personal experiences could compensate for a lack of formal training, ${ }^{77}$ such experiences should not be used as a substitute for an understanding of the research evidence.

\section{Strengths and limitations}

The realist approach has drawn out potential mechanisms that deepen understanding of CG and bereavement in primary care. A further strength is the inclusion of a broad range of literature.

The evolving definitions and terminology of CG and PGD has consequences when evaluating the practical application of the evidence. With the use of different terms, it cannot be assumed the same condition is referred to across the literature. 
The screening and selection of articles was carried out by one researcher. Decisions were regularly shared with the team to address potential biases; however, it is acknowledged that relevant articles or data may have been missed.

There have been changes in policy and practice since publication of the earlier studies included in the review, and the applicability of these findings needs to be considered within the current context.

\section{Implications for research and practice}

The authors recommend bereavement care is recognised as a legitimate part of primary care and understood as a community response (see Box 2). Response to bereavement should take a tiered, targeted approach. ${ }^{78}$

A community response to bereavement focuses on developing the existing 'assets' of community resources and creating 'compassionate communities', which includes both professionals and local informal caring networks. ${ }^{79,80}$ Social prescribing may be an appropriate means to offer bereavement support in UK primary care. ${ }^{81}$ Link worker roles could be utilised to connect patients with local services and community groups. This may allow GPs to focus attention to those with prolonged and complicated grief who may need medical attention. Primary care networks might usefully consider developing specialist bereavement services across their larger numbers of patients.

Significant knowledge gaps remain that have implications for practice and warrant further research. Targeted interventions for those experiencing CG is most effective, ${ }^{82,83}$ yet at present evidence on what, how, and for whom such treatments work is limited. ${ }^{15,82}$ Interventions such as condolence letters and death registers have been subject to little empirical evaluation. ${ }^{84}$ The efficacy of education recommendations also remains largely unknown. ${ }^{25}$

Primary care services are well-placed to provide bereavement support, but clinicians may be reluctant to take a proactive role. Bereavement can bring challenging emotions and feelings for both bereaved patients and for the clinicians managing their care. This hesitancy to be involved in bereavement is particularly concerning as primary care faces the ongoing impact of the COVID-19 pandemic, and a likely increase of bereaved patients in need of support. A community level response to bereavement that tailors support according to risk is needed to ensure that neither clinicians nor patients are left to manage the burden of bereavement, and to ensure that bereavement care becomes a standard part of practice.

Funding

The Evidence Synthesis Working Group and all the authors are funded by the National Institute for Health Research School for Primary Care Research (NIHR SPCR) [Project Number 390]. SB is also part funded by the National Institute for Health Research (NIHR) Applied Research Collaboration East of England (ARC EoE) programme. The views expressed are those of the author(s) and not necessarily those of the NIHR, the NHS or the Department of Health and Social Care.

Ethical approval

Ethics approval was not required for this review.

Provenance

Freely submitted; externally peer reviewed.

\section{Acknowledgements}

The authors would like to thank Angela Harper for her essential administrative support on this project.

\section{References}

1. Nielsen MK, Carlsen $A H$, Neergaard MA, et al. Looking beyond the mean in grief trajectories: a prospective, population-based cohort study. Soc Sci Med 2019; 232: 460-469. DOI: https://doi.org/10.1016/j.socscimed.2018. 10.007

2. Kersting A, Brähler E, Glaesmer H, Wagner B. Prevalence of complicated grief in a representative population-based sample. J Affect Disord 2011; 131(1-3): 339-343. DOI: https://doi.org/10.1016/j.jad.2010.11.032

3. World Health Organization. ICD-11 for mortality and morbidity statistics (version: 09/2020). 6B42 Prolonged grief disorder; https://icd.who.int/browse11/l-m/en\#/http://id.who.int/icd/entity/1183832314 (accessed 10 Mar 2021). 
4. King $M$, Lodwick $R$, Jones $R$, et al. Death following partner bereavement: a self-controlled case series analysis. PLoS One 2017; 12(3): e0173870. DOI: https://doi.org/10.1371/journal.pone.0173870

5. Guldin M-B, Ina Siegismund Kjaersgaard M, Fenger-Grøn M, et al. Risk of suicide, deliberate self-harm and psychiatric illness after the loss of a close relative: a nationwide cohort study. World Psychiatry 2017; 16(2): 193-199. DOI: https://doi.org/10.1002/wps.20422

6. Shah SM, Carey IM, Harris T, et al. The mental health and mortality impact of death of a partner with dementia. Int J Geriatr Psychiatry 2016; 31(8): 929-937. DOI: https://doi.org/10.1002/gps.4411

7. Stroebe M, Schut H, Stroebe W. Health outcomes of bereavement. Lancet 2007; 370(9603): 1960-1973. DOI: https://doi.org/10.1016/S0140-6736(07)61816-9

8. Charlton R, Dolman E. Bereavement: a protocol for primary care. Br J Gen Pract 1995; 45(397): 427-430.

9. Foggin $\mathrm{E}, \mathrm{McD}$ onnell $\mathrm{S}$, Cordingley $\mathrm{L}$, et al. GPs' experiences of dealing with parents bereaved by suicide: a qualitative study. Br J Gen Pract 2016; 66(651): e737-e746. DOI: https://doi.org/10.3399/bjgp16X686605

10. Nagraj $\mathrm{S}$, Barclay $\mathrm{S}$. Bereavement care in primary care: a systematic literature review and narrative synthesis. $\mathrm{Br} \mathrm{J}$ Gen Pract 2011; 61(582): e42-e48. DOI: https://doi.org/10.3399/bjgp11X549009

11. Ghesquiere AR, Patel SR, Kaplan DB, Bruce ML. Primary care providers' bereavement care practices: recommendations for research directions. Int J Geriatr Psychiatry 2014; 29(12): 1221-1229. DOI: https://doi.org/10. 1002/gps.4157

12. National Palliative and End of Life Care Partnership. Ambitions for palliative and end of life care: a national framework for local action 2015-2020. 2015; http://endoflifecareambitions.org.uk/wp-content/uploads/2015/09/ Ambitions-for-Palliative-and-End-of-Life-Care.pdf (accessed 10 Mar 2021).

13. Arthur A, Wilson E, James $M$, et al Bereavement care services: a synthesis of the literature. London: Department of Health; 2011.

14. Hewison A, Zafar S, Efstathiou N. Bereavement support in the UK - a rapid evidence assessment. Birmingham: Sue Ryder/University of Birmingham; 2019.

15. Harrop E, Morgan F, Longo M, et al. The impacts and effectiveness of support for people bereaved through advanced illness: a systematic review and thematic synthesis. Palliat Med 2020; 34(7): 871-888. DOI: https://doi. org/10.1177/0269216320920533

16. The National Council for Palliative Care. Life after death: six steps to improve support in bereavement. London: NCPC; 2014

17. Eisma MC, Boelen PA, Lenferink LIM. Prolonged grief disorder following the coronavirus (COVID-19) pandemic. Psychiatry Res 2020; 288: 113031. DOI: https://doi.org/10.1016/j.psychres.2020.113031

18. Lobb EA, Kristjanson LJ, Aoun SM, et al. Predictors of complicated grief: a systematic review of empirical studies. Death Stud 2010; 34(8): 673-698. DOI: https://doi.org/10.1080/07481187.2010.496686

19. Burke LA, Neimeyer RA. Prospective risk factors for complicated grief: A review of the empirical literature. In: Stroebe M, Schut H, van den Bout J, eds. Complicated Grief: Scientific Foundations for Health Care Professionals. New York, NY: Routledge/Taylor \& Francis Group; 2013. 145-161.

20. Bruinsma SM, Tiemeier HW, Verkroost-van Heemst J, et al. Risk factors for complicated grief in older adults. J Palliat Med 2015; 18(5): 438-446. DOI: https://doi.org/10.1089/jpm.2014.0366

21. Newsom $C$, Stroebe MS, Schut $H$, et al. Community-Based counseling reaches and helps bereaved people living in low-income households. Psychother Res 2019; 29(4): 479-491. DOI: https://doi.org/10.1080/10503307.2017. 1377359

22. Petrova M, Barclay S, Wellwood I. Realist review of the management of complicated grief in primary care and community settings: what works, for whom, under what circumstances and how in identifying and managing bereaved patients experiencing complicated grief (CRD42018109092). 2018PROSPERO; https://www.crd.york.ac. uk/PROSPERO/display_record.php?ID=CRD42018109092\&ID=CRD42018109092 (accessed 6 Apr 2021).

23. Pawson R. Evidence-Based Policy: A Realist Perspective. London: Sage; 2006.

24. Morris S, Schaefer K, Rosowsky E. Primary care for the elderly bereaved: recommendations for medical education. J Clin Psychol Med Settings 2018; 25(4): 463-470. DOI: https://doi.org/10.1007/s10880-018-9556-9

25. Guldin $M-B$, Vedsted $P$, Jensen $A B$, et al. Bereavement care in general practice: a cluster-randomized clinical trial. Fam Pract 2013; 30(2): 134-141. DOI: https://doi.org/10.1093/fampra/cms053

26. Williams $\mathrm{K}$, Thompson C, Morris D. Prolonged grief: applying the evidence in the primary care setting - issues brief for primary health networks. Wollongong: University of Wollongong, Centre for Health Service Development, Australian Health Services Research Institute; 2017.

27. Lemkau JP, Mann B, Little D, et al. A questionnaire survey of family practice physicians' perceptions of bereavement care. Arch Fam Med 2000; 9: 822-829. DOI: https://doi.org/10.1001/archfami.9.9.822

28. Wiles R, Jarrett N, Payne S, Field D. Referrals for bereavement counselling in primary care: a qualitative study. Patient Educ Couns 2002; 48(1): 79-85. DOI: https://doi.org/10.1016/S0738-3991(02)00068-X

29. Munro CM. Bereavement care. Br J Gen Pract 1999; 49(438): 66.

30. Mathieson L, Frullani KD. Bereavement and coping with loss. InnovAiT 2016; 9(12): 762-767. DOI: https://doi.org/ 10.1177/1755738016634380

31. Stephen Al, Wilcock SE, Wimpenny P. Bereavement care for older people in healthcare settings: qualitative study of experiences. Int J Older People Nurs 2013; 8(4): 279-289. DOI: https://doi.org/10.1111/j.1748-3743.2012. 00319.x

32. Birtwistle J, Payne S, Smith P, Kendrick T. The role of the district nurse in bereavement support. J Adv Nurs 2002; 38(5): 467-478. DOI: https://doi.org/10.1046/j.1365-2648.2002.02208.x

33. Johnson A. Role of district and community nurses in bereavement care: a qualitative study. Br J Community Nurs 2015; 20(10): 494-501. DOI: https://doi.org/10.12968/bjcn.2015.20.10.494 
34. Chang E, Bidewell J, Hancock K, et al. Community palliative care nurse experiences and perceptions of follow-up bereavement support visits to carers. Int J Nurs Pract 2012; 18(4): 332-339. DOI: https://doi.org/10.1111/j.1440172X.2012.02046.X

35. Saunderson EM, Ridsdale L. General practitioners' beliefs and attitudes about how to respond to death and bereavement: qualitative study. BMJ 1999; 319(7205): 293-296. DOI: https://doi.org/10.1136/bmj.319.7205.293

36. Field D. Special not different: general practitioners' accounts of their care of dying people. Soc Sci Med 1998; 46(9): 1111-1120. DOI: https://doi.org/10.1016/S0277-9536(97)10041-7

37. Mazza D. Bereavement in adult life. GPs should be accessible, not intrusive. BMJ 1998; 317(7157): 538-539. DOI: https://doi.org/10.1136/bmj.317.7157.538a

38. Bowskill SJ. General practitioners' role in emergencies. BMJ 1995; 311(7010): 951-952. DOI: https://doi.org/10. 1136/bmj.311.7010.951c

39. Lee E, Kessler D. Bereavement care. Br J Gen Pract 1995; 45(401): 689.

40. O'Connor M, Breen LJ. General practitioners' experiences of bereavement care and their educational support needs: a qualitative study. BMC Med Educ 2014; 14(1): 59. DOI: https://doi.org/10.1186/1472-6920-14-59

41. Harris T, Kendrick T. Bereavement care in general practice: a survey in South Thames health region. Br J Gen Pract 1998; 48(434): 1560-1564

42. Lyttle CP. Bereavement visiting: older people's and nurses' experiences. Br J Community Nurs 2001; 6(12): 629-635. DOI: https://doi.org/10.12968/bjcn.2001.6.12.9448

43. Redshaw S, Harrison K, Johnson A, Chang E. Community nurses' perceptions of providing bereavement care. Int J Nurs Pract 2013; 19(3): 344-350. DOI: https://doi.org/10.1111/ijn.12069

44. White $P$, Ferszt $G$. Exploration of nurse practitioner practice with clients who are grieving. $J$ Am Acad Nurse Pract 2009; 21(4): 231-240. DOI: https://doi.org/10.1111/j.1745-7599.2009.00398.x

45. Main J. Improving management of bereavement in general practice based on a survey of recently bereaved subjects in a single general practice. Br J Gen Pract 2000; 50(460): 863-866.

46. Schers $\mathrm{H}$, van de Ven $\mathrm{C}$, van den Hoogen $\mathrm{H}$, et al. Patients' needs for contact with their GP at the time of hospital admission and other life events: a quantitative and qualitative exploration. Ann Fam Med 2004; 2(5): 462-468. DOI: https://doi.org/10.1370/afm.231

47. Dangler LA, O'Donnell J, Gingrich C, Bope ET. What do family members expect from the family physician of a deceased loved one? Fam Med 1996; 28(10): 694-697.

48. Feigelman W, Sanford RL, Cerel J. Do primary care physicians help the bereaved with their suicide losses: loss survivor perceptions of helpfulness from physicians. Omega 2020; 80(3): 476-489. DOI: https://doi.org/10.1177/ 0030222817742822

49. Blyth AC. Audit of terminal care in a general practice. BMJ 1990; 300(6730): 983-986. DOI: https://doi.org/10. 1136/bmj.300.6730.983

50. Thompson CJ, Williams K, Masso MR, et al Research into services and needs for people experiencing complicated grief: final report. Wollongong: University of Wollongong, Centre for Health Service Development, Australian Health Services Research Institute; 2017.

51. Cartwright A. The role of the general practitioner in helping the elderly widowed. J R Coll Gen Pract 1982; 32(237): 215-227.

52. Dowrick C. Self-Assessment by elderly people-a means of identifying unmet need in primary care. Health Soc Care Community 1993; 1(5): 289-296. DOI: https://doi.org/10.1111/j.1365-2524.1993.tb00230.x

53. Nic an Fhaili M, Flynn N, Dowling S. Experiences of suicide bereavement: a qualitative study exploring the role of the GP. Br J Gen Pract 2016; 66(643): e92-e98. DOI: https://doi.org/10.3399/bjgp16X683413

54. Barclay S, Todd C, Grande G, Lipscombe J. How common is medical training in palliative care? A postal survey of general practitioners. Br J Gen Pract 1997; 47(425): 800-804.

55. Barclay $S$, Wyatt $P$, Shore $S$, et al. Caring for the dying: how well prepared are general practitioners? A questionnaire study in Wales. Palliat Med 2003; 17(1): 27-39. DOI: https://doi.org/10.1191/ 0269216303 pm665oa

56. Low J, Cloherty M, Wilkinson S, et al. A UK-wide postal survey to evaluate palliative care education amongst general practice registrars. Palliat Med 2006; 20(4): 463-469. DOI: https://doi.org/10.1191/0269216306pm1140oa

57. Payne S, Jarrett N, Wiles R, Field D. Counselling strategies for bereaved people offered in primary care. Couns Psychol Q 2002; 15(2): 161-177. DOI: https://doi.org/10.1080/09515070110115680

58. Lloyd-Williams M. Bereavement referrals to a psychiatric service: an audit. Eur J Cancer Care 1995; 4(1): 17-19. DOI: https://doi.org/10.1111/j.1365-2354.1995.tb00048.x

59. Zambrano SC, Barton CA. On the journey with the dying: how general practitioners experience the death of their patients. Death Stud 2011; 35(9): 824-851. DOI: https://doi.org/10.1080/07481187.2011.553315

60. Johnson A. Analysing the role played by district and community nurses in bereavement support. $\mathrm{Br} \mathrm{J}$ Community Nurs 2015; 20(6): 272-277. DOI: https://doi.org/10.12968/bjen.2015.20.6.272

61. Brownhill S, Chang E, Bidewell J, Johnson A. A decision model for community nurses providing bereavement care. Br J Community Nurs 2013; 18(3): 133-139. DOI: https://doi.org/10.12968/bjcn.2013.18.3.133

62. Monroe B, Smith P. The value of a single structured bereavement visit. British Journal of Community Health Nursing 1997; 2(5): 225-228. DOI: https://doi.org/10.12968/bjch.1997.2.5.7301

63. Ghesquiere AR, Patel SR, Kaplan DB, Bruce ML. Primary care providers' bereavement care practices: recommendations for research directions. Int J Geriatr Psychiatry 2014; 29(12): 1221-1229. DOI: https://doi.org/10. 1002/gps.4157

64. Woof WR, Carter YH. The grieving adult and the general practitioner: a literature review in two parts (Part 1). Br J Gen Pract 1997; 47(420): 443-448. 
65. Woof WR, Carter $\mathrm{YH}$. The grieving adult and the general practitioner: a literature review in two parts (Part 2). Br $\mathrm{J}$ Gen Pract 1997; 47(421): 509-514.

66. Dodd A, Guerin S, Delaney S, Dodd P. Complicated grief: knowledge, attitudes, skills and training of mental health professionals: a systematic review. Patient Educ Couns 2017; 100(8): 1447-1458. DOI: https://doi.org/10.1016/j. pec.2017.03.010

67. Dietl L, Wagner B, Fydrich T. User acceptability of the diagnosis of prolonged grief disorder: how do professionals think about inclusion in ICD-11? J Affect Disord 2018; 229: 306-313. DOI: https://doi.org/10.1016/j.jad.2017.12. 095

68. Davis EL, Deane FP, Barclay GD, et al. Attitudes of palliative care clinical staff toward prolonged grief disorder diagnosis and grief interventions. Palliat Support Care 2018; 16(4): 388-395. DOI: https://doi.org/10.1017/ S1478951517000505

69. Bandini J. The medicalization of bereavement: (ab)normal grief in the DSM-5. Death Stud 2015; 39(6): 347-352 DOI: https://doi.org/10.1080/07481187.2014.951498

70. Park S, Abrams R, Wong G, et al. Reorganisation of general practice: be careful what you wish for. Br J Gen Pract 2019; 69(687): 517-518. DOI: https://doi.org/10.3399/bjgp19X705941

71. Seymour B, Bushnell J, Dobson S. Good grief: older people's experiences of partner bereavement. London: Independent Age; 2018.

72. Joachim G, Acorn S. Stigma of visible and invisible chronic conditions. J Adv Nurs 2000; 32(1): 243-248. DOI: https://doi.org/10.1046/j.1365-2648.2000.01466.x

73. Wainwright V, Cordingley L, Chew-Graham CA, et al. Experiences of support from primary care and perceived needs of parents bereaved by suicide: a qualitative study. Br J Gen Pract 2020; 70(691): e102-e110. DOI: https:// doi.org/10.3399/bjgp20X707849

74. Eisma MC, Te Riele B, Overgaauw M, Doering BK. Does prolonged grief or suicide bereavement cause public stigma? A vignette-based experiment. Psychiatry Res 2019; 272: 784-789. DOI: https://doi.org/10.1016/j.psychres. 2018.12.122

75. Dawson J. Borderlands: the difficulty of the liminal in primary care. Br J Gen Pract 2020; 70(694): 242. DOI: https:// doi.org/10.3399/bjgp20X709649

76. Wakefield D, Fleming E, Howorth K, et al. Inequalities in awareness and availability of bereavement services in north-east England. BMJ Support Palliat Care 2020: bmjspcare-2020-002422: 23 Sep 2020. DOI: https://doi.org/10. 1136/bmjspcare-2020-002422

77. Chan WCH, Tin AF. Beyond knowledge and skills: self-competence in working with death, dying, and bereavement. Death Stud 2012; 36(10): 899-913. DOI: https://doi.org/10.1080/07481187.2011.604465

78. National Institute for Health and Care Excellence. Improving supportive and palliative care for adults with cancer. London: NICE; 2004

79. Aoun SM, Breen LJ, Howting DA, et al. Who needs bereavement support? a population based survey of bereavement risk and support need. PLoS One 2015; 10(3): e0121101. DOI: https://doi.org/10.1371/journal.pone. 0121101

80. Breen LJ, Aoun SM, O'Connor M, Rumbold B. Bridging the gaps in palliative care bereavement support: an international perspective. Death Stud 2014; 38(1-5): 54-61. DOI: https://doi.org/10.1080/07481187.2012.725451

81. NHS England. Investment and evolution: a five-year framework for GP contract reform to implement The NHS Long Term Plan. 2019; https://www.england.nhs.uk/wp-content/uploads/2019/01/gp-contract-2019.pdf (accessed 10 Mar 2021).

82. Doering BK, Eisma MC. Treatment for complicated grief: state of the science and ways forward. Curr Opin Psychiatry 2016; 29(5): 286-291. DOI: https://doi.org/10.1097/YCO.0000000000000263

83. García JA, Landa V, Grandes G, et al. Effectiveness of "primary bereavement care" for widows: a cluster randomized controlled trial involving family physicians. Death Stud 2013; 37(4): 287-310. DOI: https://doi.org/10. 1080/07481187.2012.722041

84. Beaumont B, Hurwitz B. Is it possible and worth keeping track of deaths within general practice? Results of a 15 year observational study. Qual Saf Health Care 2003; 12(5): 337-342. DOI: https://doi.org/10.1136/qhc.12.5.337

85. Wong G. Data gathering in realist reviews: looking for needles in haystacks. In: Emmel N, Greenhalgh J, Manzano A, eds. Doing Realist Research. London: SAGE Publications Ltd; 2018. 86. 131-146. 